\title{
Awareness of olfactory impairment in a cohort of patients with CNGB1-associated retinitis pigmentosa
}

\author{
Farid Afshar ${ }^{1}$ - Gavin Arno ${ }^{1,2} \cdot$ Rola Ba-Abbad ${ }^{1,2} \cdot$ Simona Degli Esposti ${ }^{1} \cdot$ Michel Michaelides $^{1,2}$. \\ Andrew R. Webster ${ }^{1,2} \cdot$ Omar A. Mahroo $\mathbb{1}^{1,2,3,4}$
}

Received: 19 August 2019 / Accepted: 12 September 2019 / Published online: 30 September 2019

(c) The Royal College of Ophthalmologists 2019

\section{To the Editor:}

The $C N G B 1$ gene encodes a protein involved in both photoreceptor and olfactory signal transduction. Patients with retinitis pigmentosa $(\mathrm{RP})$ due to bi-allelic variants in this gene were previously reported to describe no olfactory problems $[1,2]$. A subsequent quantitative study found objectively reduced olfactory function in eight of nine patients tested (89\%), with three patients (33\%) aware of their olfactory impairment [3]. Variants can occur in the N-terminal glutamic acid-rich protein (GARP) domain or in the channel domain. The GARP domain is important in rod photoreceptors, but its role in olfactory neurons is less clear; an alternatively spliced variant (CNGB1b), lacking this domain, is expressed in olfactory neurons in rats [4]. We investigated awareness of olfactory problems in our molecularly characterised cohort, and explored in which domain variants occurred.

The electronic inherited retinal disease database of Moorfields Eye Hospital was searched for patients with a molecularly confirmed diagnosis of CNGBI-associated RP. Patients were asked (by telephone or during clinic visits) whether they were aware of problems with their sense of smell. Disease-causing variants were classified by occurrence within the GARP or channel domain of the protein. It was hypothesised that patients with both variants in the channel domain might be more likely to be aware of olfactory

Omar A. Mahroo

o.mahroo@ucl.ac.uk

Genetics Service, Moorfields Eye Hospital, London, UK

2 Institute of Ophthalmology, University College London, London, UK

3 Section of Ophthalmology, King's College London, St Thomas' Hospital Campus, London, UK

4 Department of Physiology, Development and Neuroscience, University of Cambridge, Cambridge, UK impairment (as a GARP domain change would not affect translation of a splice variant that lacked this domain).

Nineteen affected patients (mean (SD) age 60 (11) years; 11 females) from 18 families were identified. Fifteen patients (79\%) were successfully contacted (mean (SD) age 61 (11) years; nine females). Of these, six (40\%) reported reduced or absent sense of smell; the remainder reported no problems. Mean age and sex distribution did not differ between those with or without awareness of olfactory impairment. Table 1 summarises patient characteristics, including causative variants, and their responses. The majority of variants have been previously reported $[3,5]$. The novel variants all had a frequency in the gnomAD database of $<0.0002$ and were predicted to be disease-causing.

Seven out of the fifteen patients had both disease-causing variants occurring in the channel domain. Of these, five reported reduced or absent sense of smell. Of the eight remaining patients (who had at least one disease-causing variant in the GARP domain), only one was aware of a reduced sense of smell. The difference in proportions was significant ( $p=0.04$, Fisher exact test, two-tailed). If combined with the subjective reports of olfactory impairment in the previous study of nine patients (only one of whom had a variant in the GARP domain) [3], the difference in proportions remained significant $(p=0.03)$.

Our findings confirm that a substantial proportion of patients with $C N G B 1$-associated RP report reduced or absent sense of smell when specifically questioned. In our cohort, patients with at least one variant in the GARP domain were less likely to report olfactory impairment, suggesting that this domain might be less important in olfaction than in photoreceptor function. Limitations of our study include reliance on subjective awareness of olfactory impairment; it is possible that objective quantitative assessment of olfaction would reveal more individuals with hyposmia. RP has hundreds of associated genes; awareness of specific non-ocular features associated with certain genotypes can assist in guiding gene testing or its interpretation. 
Table 1 Demographics, molecular changes and subjective perceived impairment in sense of smell for the patients included in the present study

\begin{tabular}{|c|c|c|c|c|c|c|c|c|}
\hline \multirow[t]{2}{*}{ Patient number } & \multirow{2}{*}{$\begin{array}{l}\text { Age } \\
\text { (years) }\end{array}$} & \multirow[t]{2}{*}{ Sex } & \multicolumn{2}{|l|}{ Variant 1} & \multicolumn{2}{|l|}{ Variant 2} & \multirow{2}{*}{$\begin{array}{l}\text { Both } \\
\text { variants in } \\
\text { channel } \\
\text { domain? }\end{array}$} & \multirow{2}{*}{$\begin{array}{l}\text { Subjective } \\
\text { sense of smell }\end{array}$} \\
\hline & & & Base change & Effect & Base change & Effect & & \\
\hline 1 & 50 & M & $\begin{array}{l}\text { c.2777-?_2958+? } \\
\text { del (Exon 28-29 } \\
\text { deletion) }\end{array}$ & p.? & $\begin{array}{l}\text { c.2777-?_2958+? } \\
\text { del (Exon 28-29 } \\
\text { deletion) }\end{array}$ & p.? & Yes & Absent \\
\hline 2 & 45 & $\mathrm{~F}$ & c. $2957 \mathrm{~A}>\mathrm{T}$ & p.(Asn986Ile) & c. $2957 \mathrm{~A}>\mathrm{T}$ & p.(Asn986Ile) & Yes & Normal \\
\hline 3 & 68 & M & c. $2285 \mathrm{G}>\mathrm{A}$ & p.(Arg762His) & c. $2285 \mathrm{G}>\mathrm{A}$ & p.(Arg762His) & Yes & Normal \\
\hline 4 & 53 & $\mathrm{~F}$ & c.2544dupG & p.(Leu849Alafs*3) & c.2544dupG & p.(Leu849Alafs*3) & Yes & Reduced \\
\hline 5 & 64 & $\mathrm{~F}$ & c. $2957 \mathrm{~A}>\mathrm{T}$ & p.(Asn986Ile) & c.2544dupG & p.(Leu849Alafs*3) & Yes & Reduced \\
\hline 6 & 56 & M & c.1729delG & p.(Glu577Serfs*6) & c. $1729 \mathrm{delG}$ & p.(Glu577Serfs*6) & Yes & Reduced \\
\hline 7 & 71 & $\mathrm{~F}$ & c. $2676 \mathrm{C}>\mathrm{A}$ & p. $($ Tyr892*) & c. $2980 \mathrm{G}>\mathrm{T}$ & p.(Glu994*) & Yes & Reduced \\
\hline 8 & 68 & $\mathrm{~F}$ & c. $2957 \mathrm{~A}>\mathrm{T}$ & p.(Asn986Ile) & c. $534+1 \mathrm{G}>\mathrm{A}$ & Splice defect & No & Normal \\
\hline 9 & 42 & M & c.2544dupG & p.(Leu849Alafs*3) & c. $262 \mathrm{C}>\mathrm{T}$ & p. $(\mathrm{G} \ln 88 *)$ & No & Normal \\
\hline 10 & 82 & M & c. $2540 \mathrm{G}>\mathrm{A}$ & p.(Gly847Glu) & c. $346 \mathrm{C}>\mathrm{T}$ & p. $\left(\mathrm{G} \ln 116^{*}\right)$ & No & Normal \\
\hline 11 & 59 & $\mathrm{~F}$ & c. $262 \mathrm{C}>\mathrm{T}$ & p. $\left(\mathrm{G} \ln 88^{*}\right)$ & c. $664 \mathrm{C}>\mathrm{T}$ & p. $\left(\mathrm{G} \ln 222^{*}\right)$ & No & Normal \\
\hline 12 & 67 & $\mathrm{~F}$ & c. $2258 \mathrm{~T}>\mathrm{A}$ & p.(Leu753*) & c. $807 \mathrm{G}>\mathrm{C}$ & p.(Gln269His) & No & Normal \\
\hline 13 & 63 & $\mathrm{~F}$ & c. $413-1 \mathrm{G}>\mathrm{A}$ & Splice defect & c. $413-1 \mathrm{G}>\mathrm{A}$ & Splice defect & No & Absent \\
\hline 14 & 69 & $\mathrm{~F}$ & c. $952 \mathrm{C}>\mathrm{T}$ & p. $\left(\mathrm{G} \ln 318^{*}\right)$ & c. $2957 \mathrm{~A}>\mathrm{T}$ & p.(Asn986Ile) & No & Normal \\
\hline 15 & 64 & M & c. $952 \mathrm{C}>\mathrm{T}$ & p. $\left(\mathrm{G} \ln 318^{*}\right)$ & c. $2957 \mathrm{~A}>\mathrm{T}$ & p.(Asn986Ile) & No & Normal \\
\hline
\end{tabular}

Patients 14 and 15 are siblings. The transcript ID for variant annotation is NM_001297.4. The following variants have not been previously reported in the context of $C N G B 1$-associated retinitis pigmentosa (frequency in the gnomAD database, https://gnomad.broadinstitute.org, accessed 6 May 2019 , of each allele is also given): p.(Gln116*), 4.02 $\times 10^{-6}$; p(.Glu577Serfs*6), not found in gnomAD; p.(Arg762His), $1.61 \times 10^{-5}$; p.(Gly847Glu), $8.01 \times 10^{-6}$; p. (Tyr892*), not found in gnomAD; p.(Glu994*), not found in gnomAD. All were predicted to be disease-causing (http://www.mutationtaster.org/, accessed 6 May 2019). c.534 $+1 \mathrm{G}>\mathrm{A}$ affects a splice donor site, and has a frequency in gnomAD of $3.63 \times 10^{-5}$. Exon 28-29 deletion is not found in gnomAD

Funding Wellcome Trust, Fight for Sight UK, NIHR Biomedical Research Centre at Moorfields Eye Hospital and the UCL Insitute of Ophthalmology. The views expressed are those of the authors and not the funding organisations.

\section{Compliance with ethical standards}

Conflict of interest The authors declare that they have no conflict of interest.

Publisher's note Springer Nature remains neutral with regard to jurisdictional claims in published maps and institutional affiliations.

\section{References}

1. Bareil C, Hamel CP, Delague V, Arnaud B, Demaille J, Claustres $\mathrm{M}$. Segregation of a mutation in CNGB1 encoding the beta-subunit of the rod cGMP-gated channel in a family with autosomal recessive retinitis pigmentosa. Hum Genet. 2001;108:328-34.

2. Fradin M, Colin E, Hannouche-Bared D, Audo I, Sahel JA, Biskup $\mathrm{S}$, et al. Run of homozygosity analysis reveals a novel nonsense variant of the CNGB1 gene involved in retinitis pigmentosa 45 . Ophthalmic Genet. 2016;37(Sep):357-9. https://doi.org/10.3109/ 13816810.2015.1087578.

3. Charbel Issa P, Reuter P, Kühlewein L, Birtel J, Gliem M, Tropitzsch A, et al. Olfactory dysfunction in patients with CNGB1-associated retinitis pigmentosa. JAMA Ophthalmol. 2018;136:761-9. https://doi.org/10.1001/jamaophthalmol.2018. 1621.

4. Bönigk W, Bradley J, Müller F, Sesti F, Boekhoff I, Ronnett GV, et al. The native rat olfactory cyclic nucleotide-gated channel is composed of three distinct subunits. J Neurosci. 1999;19: 5332-47.

5. Ba-Abbad R, Holder GE, Robson AG, Neveu MM, Waseem N, Arno $\mathrm{G}$, et al. Isolated rod dysfunction associated with a novel genotype of CNGB1. Am J Ophthalmol Case Rep. 2019;14:83-6. https://doi.org/10.1016/j.ajoc.2019.03.004. 